\title{
Piezoresistive carbon-based composites for sensor applications: Effects of polarity and non-rubber components on shape recovery
}

\author{
Y. Nakaramontri ${ }^{1,4^{*}}$, C. Kummerlöwe ${ }^{2}$, C. Nakason ${ }^{1}$, S. Pichaiyut ${ }^{1}$, S. Wisunthon ${ }^{1}$, F. Clemens ${ }^{3}$ \\ ${ }^{1}$ Faculty of Science and Industrial Technology, Prince of Songkla University, 84000 Surat Thani, Thailand \\ ${ }^{2}$ Faculty of Engineering and Computer Science, University of Applied Sciences Osnabrück, 49076 Osnabrück, Germany \\ ${ }^{3}$ EMPA Dübendorf, Überlandstrasse 129, 8600 Dübendorf, Switzerland \\ ${ }^{4}$ Present address: Department of Chemistry, King Mongkut's University of Technology Thonburi, Bangkok, Thailand
}

Received 9 January 2020; accepted in revised form 27 March 2020

\begin{abstract}
Natural rubber (NR) composites filled with carbon nanotubes (CNT), and carbon black (CB) were prepared. Also, other rubber matrices were tested, namely epoxidized-NR (ENR) and isoprene rubber (IR). The aim was to examine the effects of polarity and non-rubber constituents in rubber on mechanical and piezoresistive sensor properties. Thus, the relative resistances during extension were determined under static (stepwise) and dynamic (cycling) deformation of the composites. It was found that ENR-CNT/CB exhibited mechanical properties superior to NR-CNT/CB and IR-CNT/CB. This is attributed to the chemical ENR-CNT/CB linkages and physical interactions of non-rubber components with CNT/CB surfaces. This also helps the recovery of resistivity to the original value after 20 extension cycles. After 10000 cycles, the resistivity had changed by 2 orders of magnitude before showing the constant resistivity. Thus, ENR-CNT/CB composites can serve in sensors for health monitoring, motion sensors, and other related products, being cost-effective and easy-to-process materials.
\end{abstract}

Keywords: polymer composites, nanocomposites, rubber, material testing, mechanical properties

\section{Introduction}

Conductive composites based on electrically insulating rubber matrix have attracted both scientific research and industrial interest for several years [1]. The two main parts in such composites are (i) the insulating rubber matrix and (ii) the conducting filler. The filler needs to form conductive pathways in the matrix for carrying electrons, thereby making the composite a semiconductor or a conductor [2]. Such filler pathways are perturbed, by breakage and rearrangement inside the matrix, during deformations [3]. This changes the resistivity during elongation, which is known as piezoresistivity and can be used in motion sensor applications [4]. Hence, the sensitivity of a composite sensor is affected by the type of rubber matrix, and by choice of filler(s), such as carbon black (CB), carbon fiber, graphene, graphite, or carbon nanotubes (CNT) [5-9].

CNT has several advantages, especially in creating conductive paths in a rubber matrix, owing to its extremely high aspect ratio $[10,11]$. The CNT filled composites can serve in sensor applications due to exceptional electrical conductivity, which can respond to various external stimuli, such as temperature, organic solvents, vapor, strain, and damage [12]. Stress or strain in a structure under loading may need to be detected for avoiding serious damage during service, or even breakdown or collapse of the entire structure. Such sensing becomes essential when the structure is used to safeguard or transport humans or 
essential commodities [12]. However, to achieve an appropriate sensor for such use, there are requirements on cost, conductivity, flexibility and elasticity, water resistance (human presence requires comfortable levels of humidity), and mechanical properties $[13,14]$. As CNT filler is comparatively high priced, $\mathrm{CB}$ has been applied to reduce cost and to improve the electrical properties of the composites [15-17]. It was reported that the percolation threshold concentration of composites was significantly increased, while optimal conductivity increased, on adding conductive CB in CNT composites [18]. Furthermore, using $\mathrm{CB}$ also improves the sensitivity of electrical resistivity to stress and strain, due to its spherical shape that eases disconnection of conductive particles by strain, while the long cylindrical CNT particles can have sliding contact. This increases potentially the piezoresistive responsiveness, combining excellent conductivity of CNT with strain sensitivity of the electrical pathways on using CNT-CB blended filler $[12,19]$.

A flexible piezoresistive deformation sensor needs to be characterized for responses to static (stepwise) and dynamic (cycling) loading. Here, natural rubber (NR) is the main focus of interest as the matrix. Using $\mathrm{NR}$, incorporation of CNT and CB hybrid filler can keep a very stable sensor performance, showing good mechanical properties, when the composites are dynamically elongated several times [12, 20]. Also, NR composites are easy to process, cost-effective, and well-known as hydrophobic biopolymers [21], so that humidity does not affect on an NR sensor.

However, piezoresistivity not only depends on the intrinsic properties of the rubber (molecular weight, polarity, and chain entanglement) and the fillers but also their interactions [22]. To our knowledge, this correlation of rubber-filler interaction and changing of piezoresistive properties of the composites has not been reported previously. Therefore, in the present work, three alternative rubber matrices are tested, namely NR, epoxidized-NR (ENR), and isoprene rubber (IR). This aims to clarify the real effective role of the rubber matrix in a strain sensor containing CNT and $\mathrm{CB}$ as a hybrid filler. The ratio of CNT:CB was fixed at 1:1.5, which is appropriate for forming filler networks that span throughout the matrix. This follows with our previous work, which found that the composites exhibited superior mechanical, dynamical, and electrical properties after using the synergistic
CNT:CB ratio of 1:1.5 [18]. Melt blending was chosen as the mixing process, to prepare the composites with an internal mixer and a two-roll mill. This aims to optimize the state of dispersion and distribution of fillers in the rubber matrix. Furthermore, the piezoresistivity (strain sensitivity of electrical resistance) was investigated in terms of the relative change in resistance, $\Delta R / R_{0}$ ( $\Delta R$ is the change in resistance with strain, and $R_{0}$ is the initial resistance of the composite) $[12,23]$. Also, both static (stepwise) and dynamic (cycling) deformations were used to assess the mechanical properties as well as the resistivity as functions of strain or cycles. Such conductive elastomer composite sensors will have the potential for use in future soft body monitoring systems, like motion sensors, to detect body movements with high precision, or for observing and recording physical activities [24, 25].

\section{Experimental}

\subsection{Materials}

Natural rubber (NR) in the form of standard Malaysian rubber (SMR) and epoxidized-NR with 25 mol\% epoxide (i.e., ENR-25) were manufactured by Weber \& Schaer GmbH (Hamburg, Germany). Also, isoprene rubber (IR) was purchased from Fushun Yikesi New Material Co., Ltd. (Liaoning, China). The multi-walled carbon nanotubes (NC7000) with $9.5 \mathrm{~nm}$ in diameter, $c a .1 .5 \mu \mathrm{m}$ length, and $90 \%$ purity were manufactured by Nanocyl S.A. (Sambreville, Belgium). The carbon black (CB), Vulcan $\mathrm{XC} 72 \mathrm{R}$ with $30 \mathrm{~nm}$ particle diameter, was manufactured by Cabot Corporation (Texas, USA). The other compounding chemicals, namely stearic acid, zinc oxide ( $\mathrm{ZnO}$ ), 2,2'-Dithiobis-(benzothiazole) (MBTS), and sulfur curing agent were purchased from ACROS Organics, Belgium. The compounding formulations are summarized in Table 1.

Table 1. Chemical ingredients and compounding formulation of the composites.

\begin{tabular}{|l|c|}
\hline \multicolumn{1}{|c|}{ Ingredient } & $\begin{array}{c}\text { Content } \\
\text { [phr] }\end{array}$ \\
\hline Rubbers & 100 \\
\hline CNT:CB $(1: 1.5 \mathrm{phr})$ & $0-7$ \\
\hline ZnO & 5 \\
\hline Stearic acid & 1 \\
\hline MBTS & 1 \\
\hline Sulfur & 2 \\
\hline
\end{tabular}




\subsection{Preparation of rubber composites}

The rubber composites with CNT/CB hybrid filler were carefully prepared, using an internal mixer (Brabender VR GmbH \& Co. KG, Duisburg, Germany) with $60 \mathrm{rpm}$ rotor speed at $80^{\circ} \mathrm{C}$. The rubber was first masticated on an open two-roll mill (Servitech $\mathrm{GmbH}$, Wustermark, Germany) to reach a Mooney viscosity in the desired range (i.e., ML $\left.1+4\left(100^{\circ} \mathrm{C}\right)=55-60\right)$ before compounding. Filler (CNT:CB $=1: 1.5 \mathrm{phr}$ ) was mixed with ethanol in the ratio of 1:10 using ultrasonication at $80 \mathrm{~W}$ for $10 \mathrm{~min}$. It is noted that the ethanol was directly evaporated in the internal mixer during the mixing. The mixing operation was started by masticating rubber in the internal mixer for $1 \mathrm{~min}$ before adding the filler dispersed in ethanol, and the mixing continued for another $6 \mathrm{~min}$. The activators (i.e., stearic acid and $\mathrm{ZnO}$ ) and the curatives (i.e., MBTS and sulfur) were consecutively added into the rubber compound, with mixing continued until 12 min total mixing time. Also, all gum rubber compounds (i.e., the unfilled gums NR, ENR, and IR) were prepared by the same procedure and total mixing time, for comparison purposes. Eventually, the compound was passed through the $1 \mathrm{~mm}$ nip of the two-roll mill for several times to achieve optimal dispersion of filler in the rubber matrix, before conditioning at room temperature in a desiccator for at least $24 \mathrm{~h}$. Finally, rubber composite sheets with dimensions $150 \times 160 \times 2 \mathrm{~mm}^{3}$ were prepared by compression molding at $160^{\circ} \mathrm{C}$ using the cure times based on rheometer tests.

\section{Characterization}

Mechanical properties in terms of tension and compression sets of gum rubbers (NR, ENR, and IR) and their composites with CNT/CB hybrid filler were measured following ASTM D412 and ASTM D395(B), respectively. For tension set, dumbbellshaped specimens (type 5A, ISO 527) were used. Here, the samples were clamped with the holder of a tensile testing machine (Zwick GmbH \& Co., KG., Ulm, Germany) at room temperature. The samples were then elongated to $100 \%$ strain with a crosshead speed of $200 \mathrm{~mm} / \mathrm{min}$, held for $10 \mathrm{~min}$, released to $0 \%$ strain, and let stand for another $10 \mathrm{~min}$ before measuring the changes from the original dimensions. In addition, in the case of compression set, cylindrical samples were compressed in a mold and stored in a hot air oven at $100^{\circ} \mathrm{C}$ for $22 \mathrm{~h}$. The samples were then cooled down and removed from the molds, let stand for $30 \mathrm{~min}$, and the change in sample thickness was measured. The compression set $\left(C_{\mathrm{B}}\right)$ was calculated as shown by Equation (1):

$C_{\mathrm{B}}=\left[\frac{t_{0}-t_{1}}{t_{0}-t_{\mathrm{n}}}\right] \cdot 100$

where $t_{0}, t_{1}$ and $t_{\mathrm{n}}$ are the original, recovered and compressed (space in the mold during compression) thicknesses, respectively.

The electrical volume resistivity of the gum rubbers (NR, ENR, and IR) and their composites with CNT/ $\mathrm{CB}$ filler was measured at room temperature using an LCR meter (Hioki IM 3533, Hioki E.E. Corporation, Nagano, Japan) at a frequency of $50 \mathrm{~Hz}$. The sample was first placed between two parallel plates of the dielectric test fixture (16451B dielectric test fixture, Test Equipment Solutions Ltd., Berkshire, United Kingdom) with a $5 \mathrm{~mm}$ electrode diameter. The resistance $\left(R_{\mathrm{p}}\right)$ was then detected and converted to resistivity $(\rho)$ and conductivity $(\sigma)$ by using Equation (2) [26]:

$\sigma=\frac{1}{\rho}=\frac{d}{R_{\mathrm{p}} A}$

where $d$ and $A$ refer to the sample thickness and the area of an electrode, respectively.

The change in resistance $(\Delta R)$ during strain, so-called piezoresistivity, was measured using a universal tensile testing machine (Zwick GmbH \& Co. KG, Ulm, Germany) in parallel with a multimeter (Digital multimeter, Sungwon Co. Ltd., Daegu, Korea) [27]. Here, insulation grips were used to eliminate noise corrupting resistivity measurements. The dumbbell-shaped specimen (ISO527 type 5A) was then inserted between the grips aligned with the direction of extension. Then, the clamps of the tensile testing machine were set to move at the crosshead speed of $40 \mathrm{~mm} / \mathrm{min}$, as seen in Figure 1. The strained sample with the clamps was connected to an in-house built multimeter by wires. The applied voltage was around $\sim 1 \mathrm{~V}$, and resistances up to $20 \mathrm{M} \Omega$ can be measured. The maximum possible strain in this set-up was $250 \%$. The relative change of resistance $\left(\Delta R / R_{0}\right)$ was calculated, where $\Delta R$ refers to the change in resistance at a given strain, and $R_{0}$ refers to the initial resistance of the sample [12].

The relaxations of composites were determined by stepwise tensile testing. Here, the sample was initially pre-strained at the $90 \%$ strain and held for $60 \mathrm{~s}$ before releasing the force to $0 \mathrm{~N}$, and the resulting 


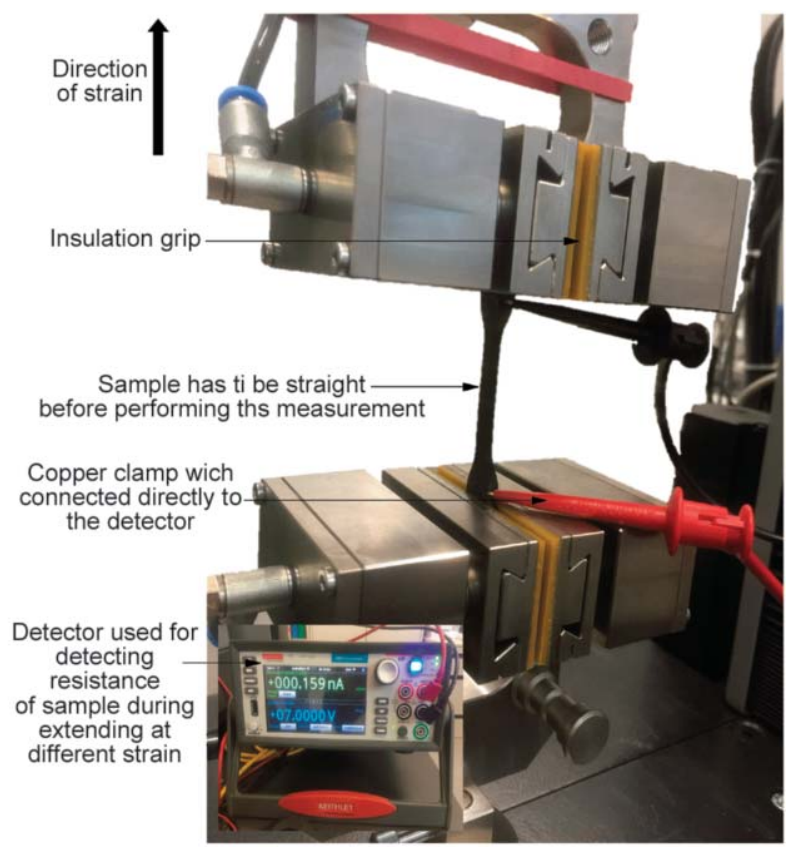

Figure 1. Instrumental setup for measuring electrical conductivity and resistivity during mechanical tensile strain.

dimension was assigned $0 \%$ strain. This aims to release prior stresses (erase effects of stress history) before performing the actual measurements [27]. It is recognized that the properties of the pure rubber and its composites are significantly influenced by the stress history that occurred from the processing and compression molding. Then, the relaxation test was started, and the sample was extended to $10 \%$ strain, held for $60 \mathrm{~s}$, and the strain was increased by $10 \%$ at each step until $80 \%$, before releasing the force and strain. This measurement was performed using a cross-head speed of $200 \mathrm{~mm} / \mathrm{min}$ to investigate the static load responses of the piezoresistive elastomer composites.

To analyze the dynamic load responses, a cycling test was performed. The sample was first pre-strained as in the recoverability measurement above. Then, the sample was consecutively extended to $80 \%$ strain [27], released to zero force, and extended again to $80 \%$, repeating this for 20 cycles using a cross-head speed of $200 \mathrm{~mm} / \mathrm{min}$ to detect the drift in force and the relative resistance of the composites at each cycle. Furthermore, numbers of cycles were measured using a combination of a Fatigue to failure tester (Monsanto $\mathrm{GmbH}$, Düsseldorf, Germany) and a Faraday cage (Fetronik GmbH, Langenfeld, Germany). Here, dumbbell-shaped specimens (ISO527 type 5A) were used and clamped to the sample holder. The cyclic test was then set for 50, 100, 500, 1000, 3000, 5000, or 10000 cycles with $50 \%$ strain amplitude. For each test run, the samples were removed, pre-conditioned at room temperature for $120 \mathrm{~s}$, and the resistance was measured with a gage at $50 \mathrm{~Hz}$ frequency connected directly to the multimeter.

The surface morphologies of composites were visualized by transmission electron microscopy (TEM) (Jeol JEM 2010, Jeol Ltd., Tokyo, Japan) with 200 kV acceleration voltage. Ultrathin slices (about 80 $90 \mathrm{~nm}$ ) were prepared using a diamond knife in the RMC-MT-X ultramicrotome (Boeckeler Instruments, Inc., Arizona, USA), under cryogenic conditions at $-100^{\circ} \mathrm{C}$. The thin samples were then mounted on 200 mesh copper grids for imaging.

\section{Results and discussion}

\subsection{Elasticity under tension and compression loads}

In order to examine the elasticity of the composites, which is one of the key factors for examining the duration of sensor application, Figure 2 shows the plots of tension and compression sets of gums NR, ENR, IR, and their composites with CNT/CB filler. It is seen that the gum NR exhibited the lowest tension and compression sets. This means that NR had the highest elasticity among the gums. This is attributed to chain entanglement in NR and storage hardening based on interactions of protein and phospholipid molecules with end groups of NR [28]. On the other hand, these phenomena do not occur in gum IR, and therefore large tension and compression sets were recorded. Considering NR, ENR, and IR composites with $\mathrm{CNT} / \mathrm{CB}$, it is seen that tension and compression sets increased with CNT/CB loading. This is due to a proportional decrease in rubber content as filler content increases. Thus, as the elastic component was lost, tension and compression sets increased. Considering at over $3 \mathrm{phr} \mathrm{CNT} / \mathrm{CB}$ where the slopes of each curve are fixed, the degree of CNT/ $\mathrm{CB}$ agglomeration in each rubber is examined. NRCNT/CB and IR-CNT/CB exhibited higher slopes than ENR-CNT/CB in both tension and compression sets. This can be explained by strong CNT/CB agglomeration, which was originated after the compounding process. With poor filler-rubber interactions, CNT/CB experienced strong re-agglomeration after compounding, controlled by depletion forces [29] that emerge from thermodynamics during the cooling of the compounds. Thus, if the compound has strong filler-rubber interaction, the re-agglomeration 

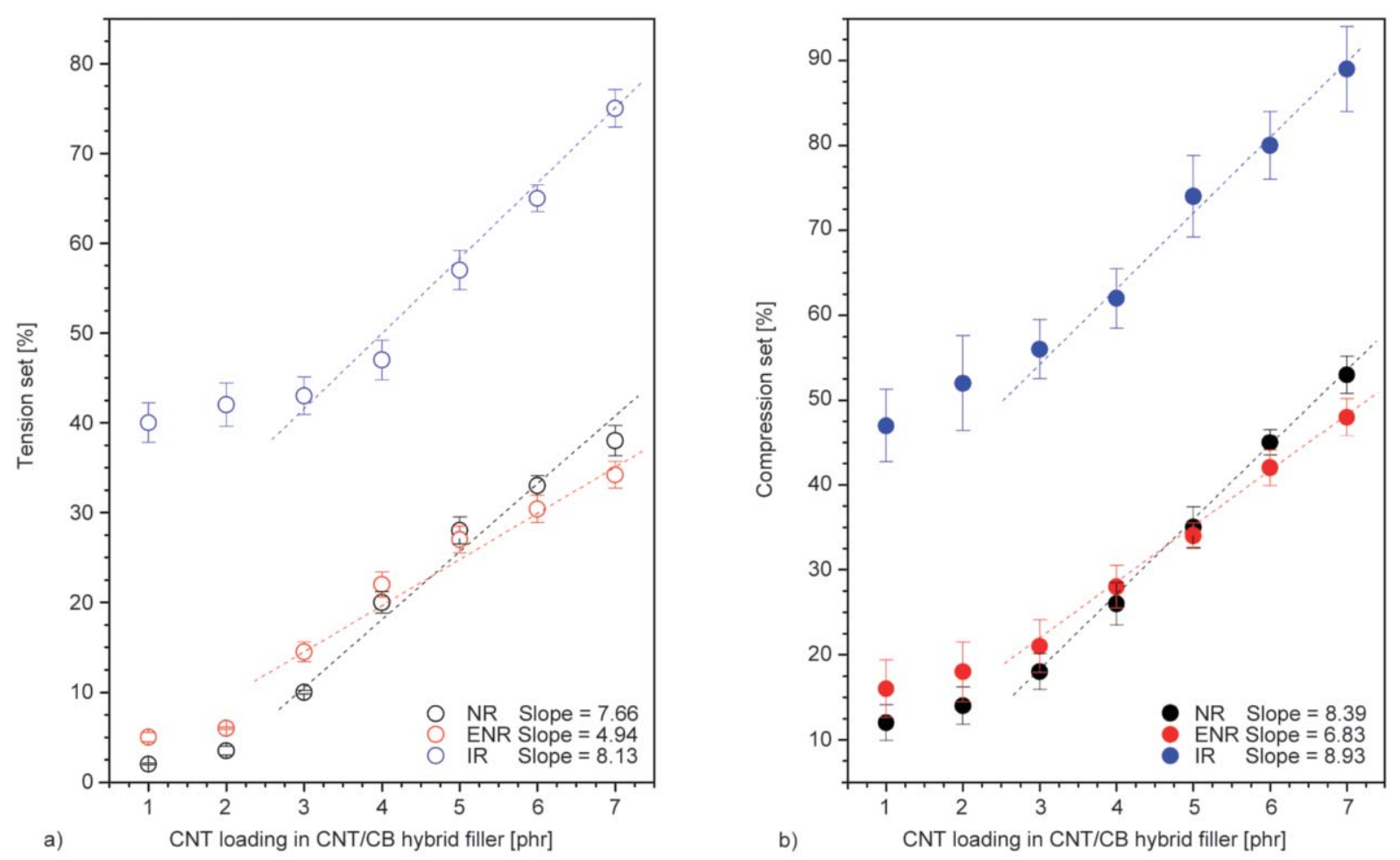

Figure 2. Tension (a) and compression (b) sets of CNT/CB composites based on NR, ENR and IR matrices. The slope was calculated only at 3-7 phr of CNT/CB. It is noted the tension and compression sets of pure NR, ENR and IR are $0.87 \pm 0.1,2.23 \pm 0.4,37 \pm 2.1 \%$ and $8 \pm 1.2,12 \pm 2.1,42 \pm 2.5 \%$, respectively.

of $\mathrm{CNT} / \mathrm{CB}$ is lesser. This causes better dispersion and distribution states of $\mathrm{CNT} / \mathrm{CB}$ in the ENR$\mathrm{CNT} / \mathrm{CB}$ composites than in either NR-CNT/CB or IR-CNT/CB. It is noted that the functional groups on ENR and CNT/CB surfaces, i.e. carboxylic and hydroxyl groups, can chemically react to form chemical linkages in ENR-CNT/CB composites [21]. This linkage is sensitive to reform after extension and compression tests. Thus, low tension and compression sets together with the lowest slope at over $3 \mathrm{phr}$ $\mathrm{CNT} / \mathrm{CB}$ were observed for ENR-CNT/CB composites. In Figure 2, it is also found that the tension and compression sets of ENR composites with 5-7 phr of CNT/CB were below those of corresponding NR composites. This corroborates the concept that strong filler-rubber interactions in the ENR gave good dispersion of the $\mathrm{CNT} / \mathrm{CB}$ hybrid filler.

However, on comparing NR-CNT/CB and IR-CNT/ $\mathrm{CB}$ composites, it is seen that NR-CNT/CB exhibited the slightly lesser slope of these two. This means that CNT/CB in NR matrix had better dispersion than in IR. This might be due to the non-rubber components, i.e. protein and phospholipids, in NR, which reacted with CNT/CB surfaces through $\pi-\pi$ stacking [30], so that re-agglomeration of $\mathrm{CNT} / \mathrm{CB}$ after compounding is prevented and this improved the filler dispersion.

\subsection{Electrical conductivity}

The electrical conductivity of the gums NR, ENR, and IR, and their composites with $\mathrm{CNT} / \mathrm{CB}$, tested at $50 \mathrm{~Hz}$, was calculated using Equation (2) and is illustrated in Figure 3. It is seen that each composite had significant differences in conductivity, affected by filler dispersion and distribution. In IR-CNT/CB composites, conductivity drastically increased after $0.5-1.0 \mathrm{phr}$ filler loading and reached optimal conductivity at approximately $3.0-4.0 \mathrm{phr}$. This is due to the re-agglomeration of $\mathrm{CNT} / \mathrm{CB}$ particles after compounding, owing to poor filler-rubber interactions [29]. Thus, the CNT/CB clusters are formed rapidly in an IR matrix, and the network sharply increased conductivity, but the composites reached optimum conductivity below NR-CNT/CB and ENR-CNT/CB. On the other hand, ENR-CNT/CB gave the highest conductivity, while the percolation threshold concentration was approximately $1.5 \mathrm{phr} \mathrm{CNT} / \mathrm{CB}$, as also seen for IR-CNT/CB composites. It is noted that the percolation threshold is the concentration of filler at which the composite transitions from an insulator to a semiconductor or a conductor [2]. Thus, higher optimal conductivity and lower percolation threshold in ENR-CNT/CB indicate better homogenous CNT/ $\mathrm{CB}$ dispersion, which facilitates forming conductive 


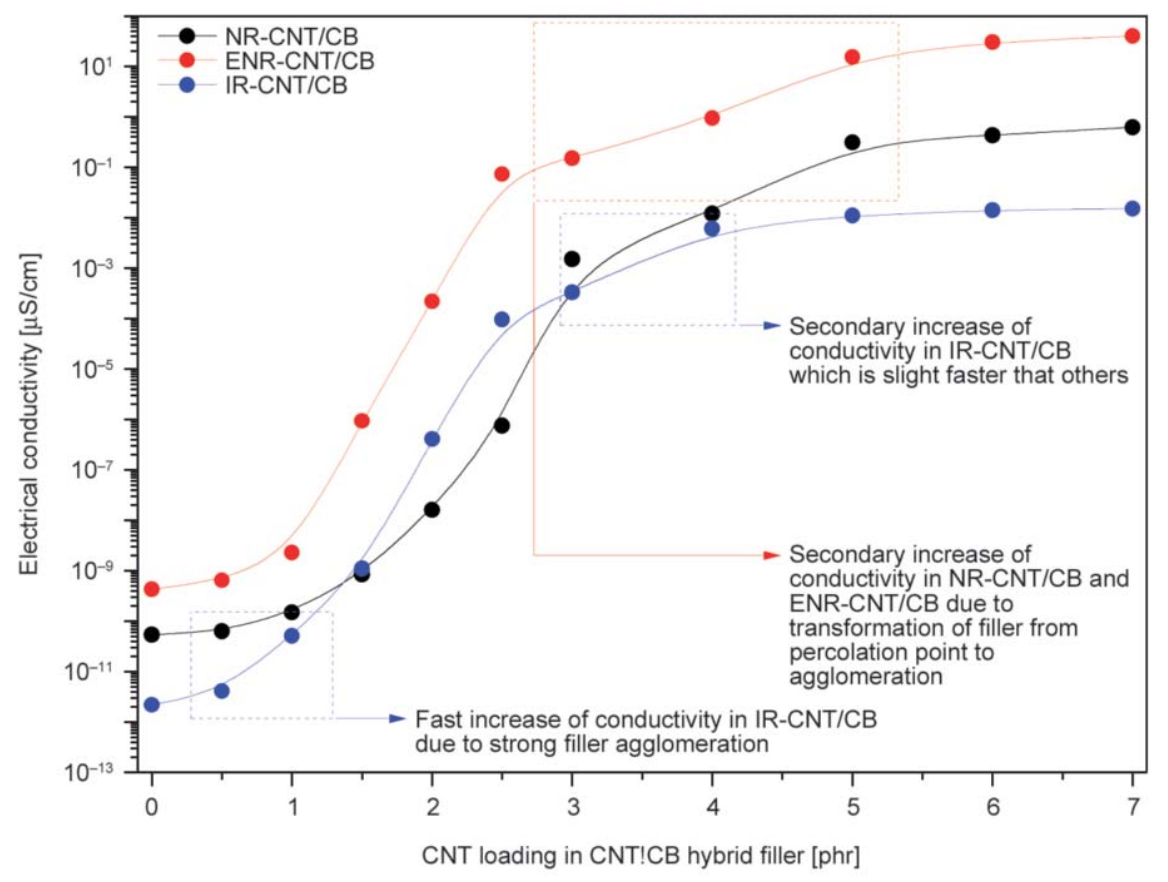

Figure 3. Electrical conductivity as a function of CNT/CB loading for gum NR, ENR, IR and their filled composites.

filler pathways throughout the ENR matrix, compared to other rubber matrices [31]. This is the rationale of better electrical conductivity for ENR-CNT/CB than for the non-polar NR and IR composites. It has to be noted that this broad percolation concentration of ENR-CNT/CB composites is officially not found in a non-flexible polymer matrix, such as polypropylene (PE), polycarbonate (PC) and ethylene/1-butene copolymer (TEPE) composites filled with CNT [3234]. Furthermore, considering the conductivity of composites beyond the percolation concentration, it is seen that ENR-CNT/CB and NR-CNT/CB composites exhibited strong secondary increases of conductivity that can be explained by filler agglomeration. That is, at the percolation concentration, each filler particle has just physically contacted others to form a continuous cover of the composite. However, beyond this loading level, excess filler concentration causes large clusters of filler in the matrix. These clusters increase conductivity significantly again before it saturates. It is seen that secondary increases in conductivity of NR-CNT/CB and ENR-CNT/CB occurred at approximately 4.0-5.0 phr. However, in IR-CNT/CB composites, this behavior was not as clear at approximately 3.0-4.0 $\mathrm{phr}$ since the filler agglomeration in the IR matrix happened very early on, due to low rubber chain entanglement, poor fillerrubber interactions, and lack of non-rubber constituents from the matrix.

\subsection{Mechanical properties and piezoresistive behavior}

\subsubsection{Tensile-strain tests}

Figure 4 shows the stress-strain responses of NR, ENR, and IR composites with 5 phr of CNT/CB hybrid filler. Here the samples were strained only to $250 \%$ to avoid strong effects from strain-induced crystallization of NR and ENR. It is seen that ENR$\mathrm{CNT} / \mathrm{CB}$ exhibited the highest stress at a given strain among the composites. This is due to intrinsic chemical interactions of the functional groups on ENR with the CNT/CB surfaces, as seen in the model proposed in Figure 5. It is noted that, during compounding, shear, heat, and moisture opened the oxirane rings on ENR, and these provide diol groups. These polar groups then reacted with the functional groups on CNT/CB surfaces, forming chemical linkages in the composites. Thus, during extension, these composites did not easily fail because of the comparatively strong filler-rubber interactions and high filler reinforcement efficiency (Figure 5a). However, the NR-CNT/CB composites had higher stresses than the IR-CNT/CB, although the rubber was pre-mixed before compounding to stabilize the molecular weight distribution in each rubber matrix [28]. There may have been physical $\pi-\pi$ interactions between the protein and phospholipids in the NR matrix and the carbon-based filler sidewalls (Figure 5b) [9]. These interactions may be the key factor protecting against 
filler re-agglomeration in the NR matrix after compounding, providing better filler dispersion than in the IR matrix. Thus, for strain-sensor applications, ENR-CNT/CB appears a better choice than the other composites with NR and IR, owing to its stronger filler-rubber interactions.
As is well-known, on considering strain sensing applications, it is not only the mechanical properties but also the electrical resistance of the composite that has to be taken into account. Figure 6 shows the relative change in resistance $\left(\Delta R / R_{0}\right)$ as a function of extension time and strain for the NR, ENR, and IR

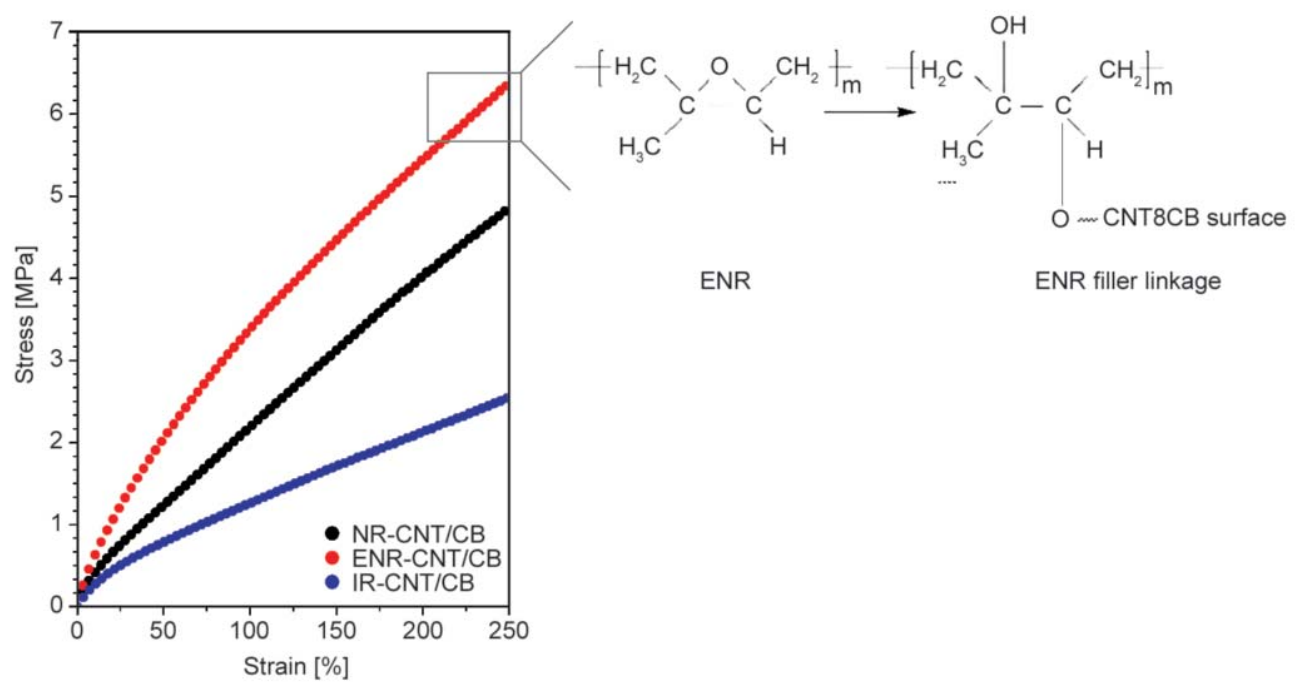

Figure 4. Stress-strain curves of NR, ENR and IR composites with $5 \mathrm{phr}$ of CNT/CB hybrid filler under up to $250 \%$ controlled strain. The sub-figure highlights chemical linkages between polar functional groups of ENR and CNT/CB surfaces.

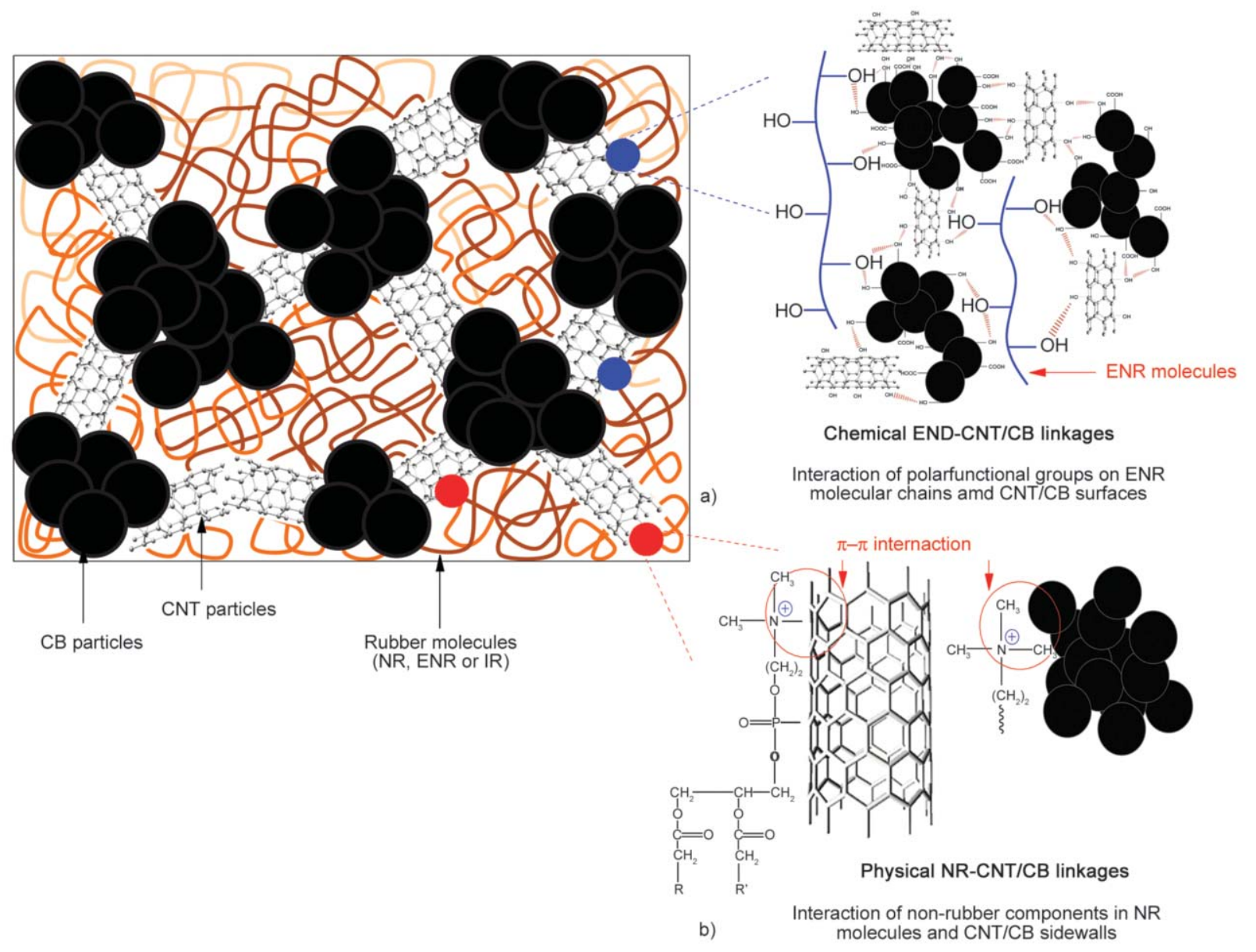

Figure 5. A proposed model of CNT/CB composites based on ENR and NR matrices due to interactions between (a) polar functional groups on ENR and CNT/CB, and (b) non-rubber components in NR and CNT/CB surfaces. 


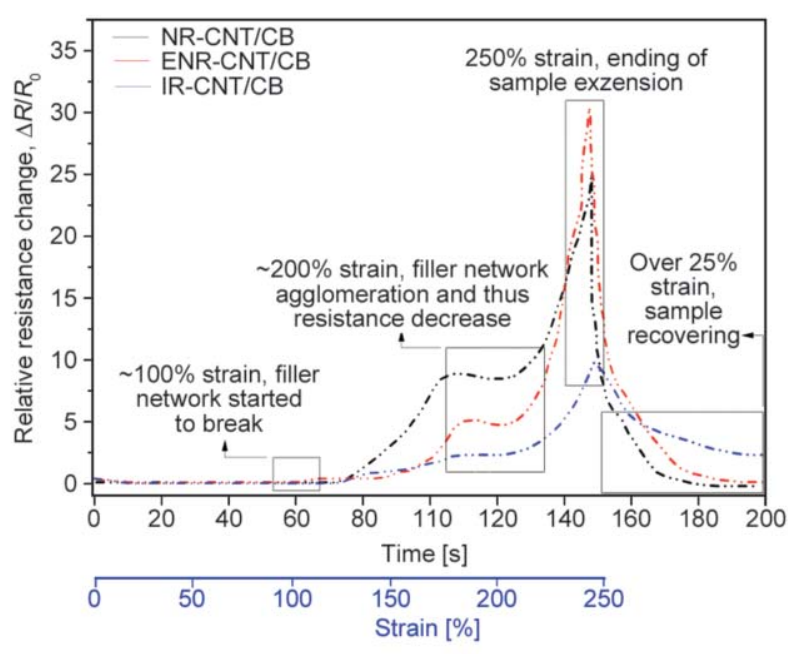

Figure 6. Relative change in electrical resistance of NR, ENR and IR composites with 5 phr of CNT/CB hybrid filler as a function of extension time and strains of $0-250 \%$.

composites with CNT/CB filler. Four regions of resistance change were found, related to the arrangement of filler particles and their clusters, during extension up to $250 \%$ strain. The first region is seen at $100-150 \%$ strains and has a sharp increase in resistance due to the breakdown of filler networks, as seen in the proposed model of Figure 7a. Here, filler networks in the rubber matrix are freely separated from each other by extension deformation. It is seen that the resistance of NR-CNT/CB and IR-CNT/CB composites drastically increased in this region, while the ENR-CNT/CB showed just a slight increase. In both NR and IR composites, there were no chemical interactions between the rubber matrix and filler surfaces resisting filler-filler separation. Thus, during extension, the filler networks were disconnected in the direction of extension, providing a sharp increase in resistance around $100-150 \%$ strain. On the other hand, the strong filler-rubber interaction in ENRCNT/CB composites (Figure 5a) caused only a slight increase in resistance in this region, with about $20 \mathrm{~s}$ duration of filler-filler breakdown, whereas only 5$10 \mathrm{~s}$ was needed for NR-CNT/CB and IR-CNT/CB composites. This affirms that the ENR-CNT/CB linkages retard deformations of filler networks in these composites. Furthermore, considering the second region at $150-220 \%$ strains, it was found that the resistance changes of the composites slightly decreased, particularly for NR-CNT/CB and ENR-CNT/CB. This suggests the re-connection of filler particles/ clusters during further extension with decreasing cross-section area of the sample, as seen in Figure 7a.
That is, most of the filler is separated from other fillers after the breakdown in the first region, and therefore free to move with the straining. At this stage, the filler can reconnect, forming conductive filler pathways [27] again. This is the rationale for decreased resistance changes in each composite. However, in the IR-CNT/CB composites, this region had less occurred. This might be explained by the strong filler agglomeration in the IR matrix, which caused fast filler re-connection since the composites have poor filler-rubber interactions and no $\pi-\pi$ coupling from non-rubber components. However, after this region, the fillers become permanently broken apart, and thus resistance strongly increased at $250 \%$ strain. The IR-CNT/CB had strong filler agglomeration, which caused poor optimal conductivity (Figure 3) and mechanical properties (Figure 4). It might be presumed that large filler agglomerates still have a short contact with each other during extension, causing lesser resistance changes. On the other hand, due to chemical interactions in ENR-CNT/CB and physical $\pi-\pi$ interactions of non-rubber components with $\mathrm{CNT} / \mathrm{CB}$ filler in NR-CNT/CB, sharp increases in resistance changes are seen. This is due to the breakdown of filler particle/clusters that rapidly disconnected filler pathways, and the resistance then depended on the insulating rubber matrix. In the last region, extension force was released, and electrical resistance then strongly decreased by re-connection of filler based on the elastic recovery of original shape [27], as seen in Figure 7b. It is seen that NR$\mathrm{CNT} / \mathrm{CB}$ and ENR-CNT/CB composites exhibited a strong decrease of resistance in only $5 \mathrm{~s}$ while IRCNT/CB showed slower molecular relaxation for about $20 \mathrm{~s}$. This matches well the observed elasticity of the composites based on tension and compression sets, see Figure 2. This means that high elasticity of the composites with NR and ENR matrices promotes fast recovery of the original resistance without strain. On the other hand, slow relaxation of the IR-CNT/ $\mathrm{CB}$ composites is due to comparatively poor elasticity. This correlates well to the estimated elasticity observed in Figure 2 and Young's modulus calculated from Figure 4 (Young's modulus of NR-CNT/ $\mathrm{CB}=4.9 \mathrm{MPa}$, ENR-CNT/CB $=7.1 \mathrm{MPa}$ and IR$\mathrm{CNT} / \mathrm{CB}=3.0 \mathrm{MPa}$ ). This is also the reason why the electrical resistances of the composites do not reach their original values. In summary, the ENR-CNT/CB composites are suited for use as strain sensors because of high elasticity (Figure 2), good electrical 


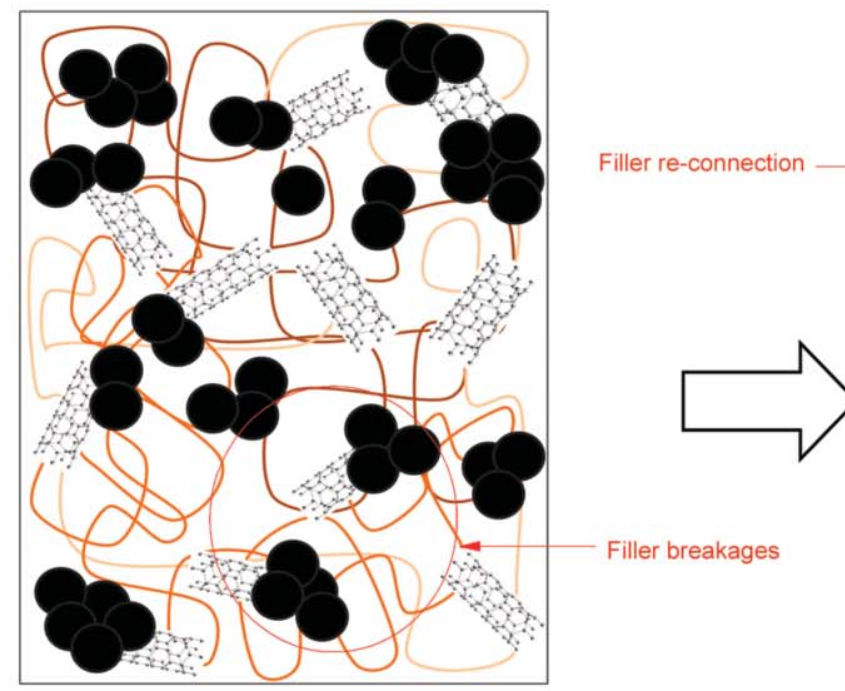

At $100-150 \%$ strain

Fillers are separated due to force straining

a)

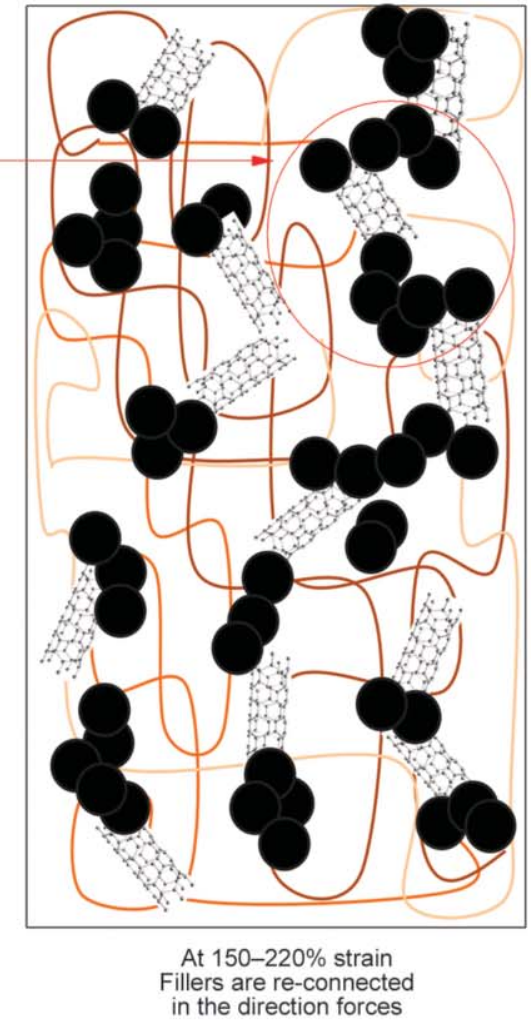

At over $250 \%$ strain
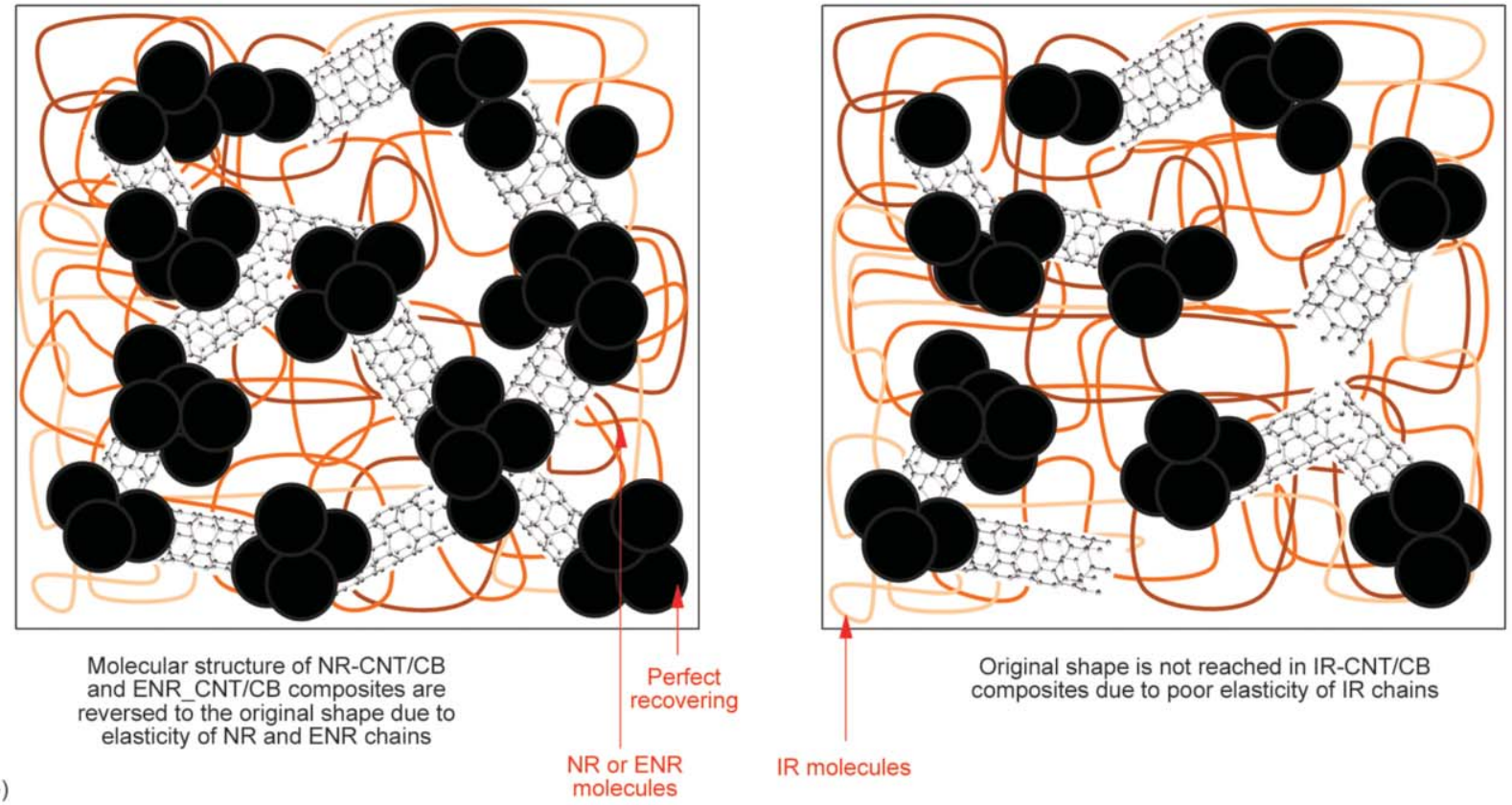

IR molecules

Figure 7. A proposed model of CNT/CB composites based on NR, ENR and IR matrices during extension for (a) 100-150\% and $150-220 \%$ strains, and (b) over $250 \%$ strain.

properties (Figure 3), good mechanical properties (Figure 4) and sensitive piezoresistivity (Figure 5). This corresponds to strong filler-rubber interactions based on reactions of polar functional groups of ENR, and on CNT and CB surfaces. However, it was found that non-rubber components (i.e., protein and phospholipids) in the NR matrix provided $\pi-\pi$ interactions with CNT and CB. This significantly improved CNT/ $\mathrm{CB}$ dispersion together with the mechanical and electrical properties of the NR-CNT/ CB composites relative to IR-CNT/CB. This $\pi-\pi$ interaction mechanism is presumed to occur also in the ENR-CNT/CB since protein and phospholipids remain in ENR after NR is converted to this modified form [28]. 


\subsubsection{Static stepwise tensile test}

To examine the relaxation by each composite, stepwise tensile tests were investigated with mechanical extension coupled with electrical resistance measurements of the composites. Here, the samples were first pre-strained to $90 \%$ with a $200 \mathrm{~mm} / \mathrm{min}$ extension speed. This aimed to erase any memory of stress history before the actual measurement. Figure 8 shows stress as a function of time and strain for the CNT/CB piezoresistive composites with NR, ENR, and IR matrices. It is seen that ENR-CNT/CB showed the highest stress among these alternatives (Figures $8 \mathrm{a}$ and $8 \mathrm{~b}$ ). This matches the chemical coupling of polar functional groups on ENR and CNT/CB surfaces, causing strong filler-rubber interactions that resist the extensional deformation. However, for sensor applications, stress as a function of strain must be considered, and this is shown in Figure $8 \mathrm{~b}$. The stress relaxation $\left(\sigma_{\max -\min }\right)$ at each strain level held for $60 \mathrm{~s}$ can be calculated, and this is plotted in Figures 9. It was found that ENR-CNT/CB and NR-CNT/CB composites exhibited stronger stress relaxation than the one with IR. This is attributed to the improved filler dispersion in ENR and NR matrices caused by chemical polar-polar bonding and physical $\pi-\pi$ interactions with the non-rubber components. These

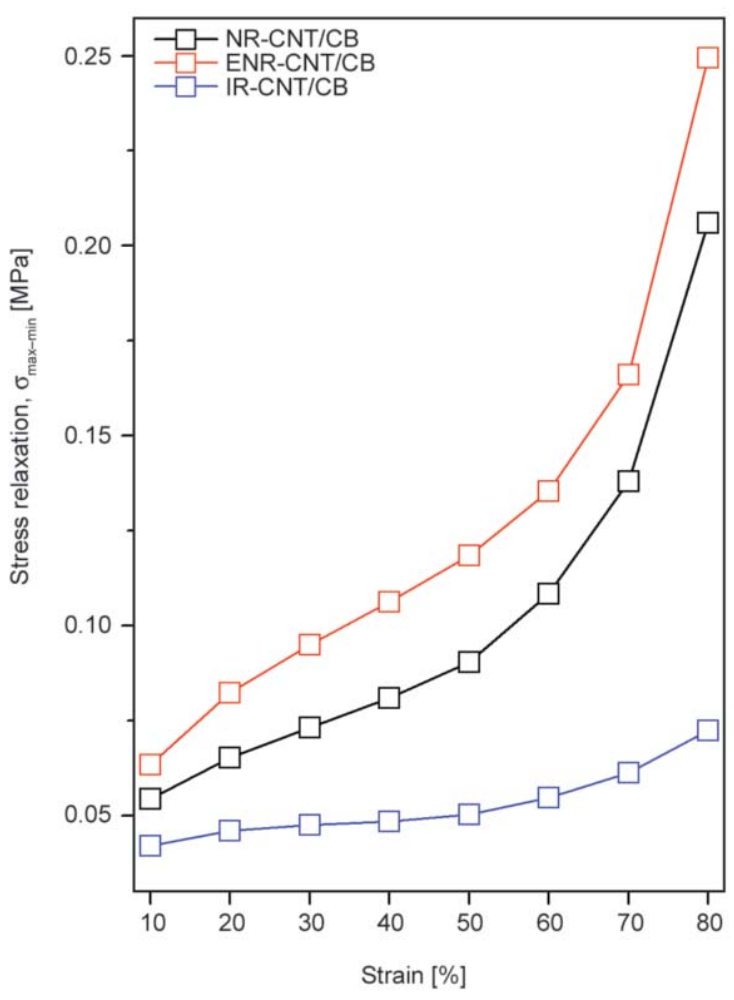

Figure 9. Stress relaxation as a function of strain for the NR, ENR and IR composites with $5 \mathrm{phr}$ of $\mathrm{CNT} / \mathrm{CB}$ hybrid filler. The omax-min values are the differences between maximal and minimal stresses at each strain level tested in the stepwise sequence.
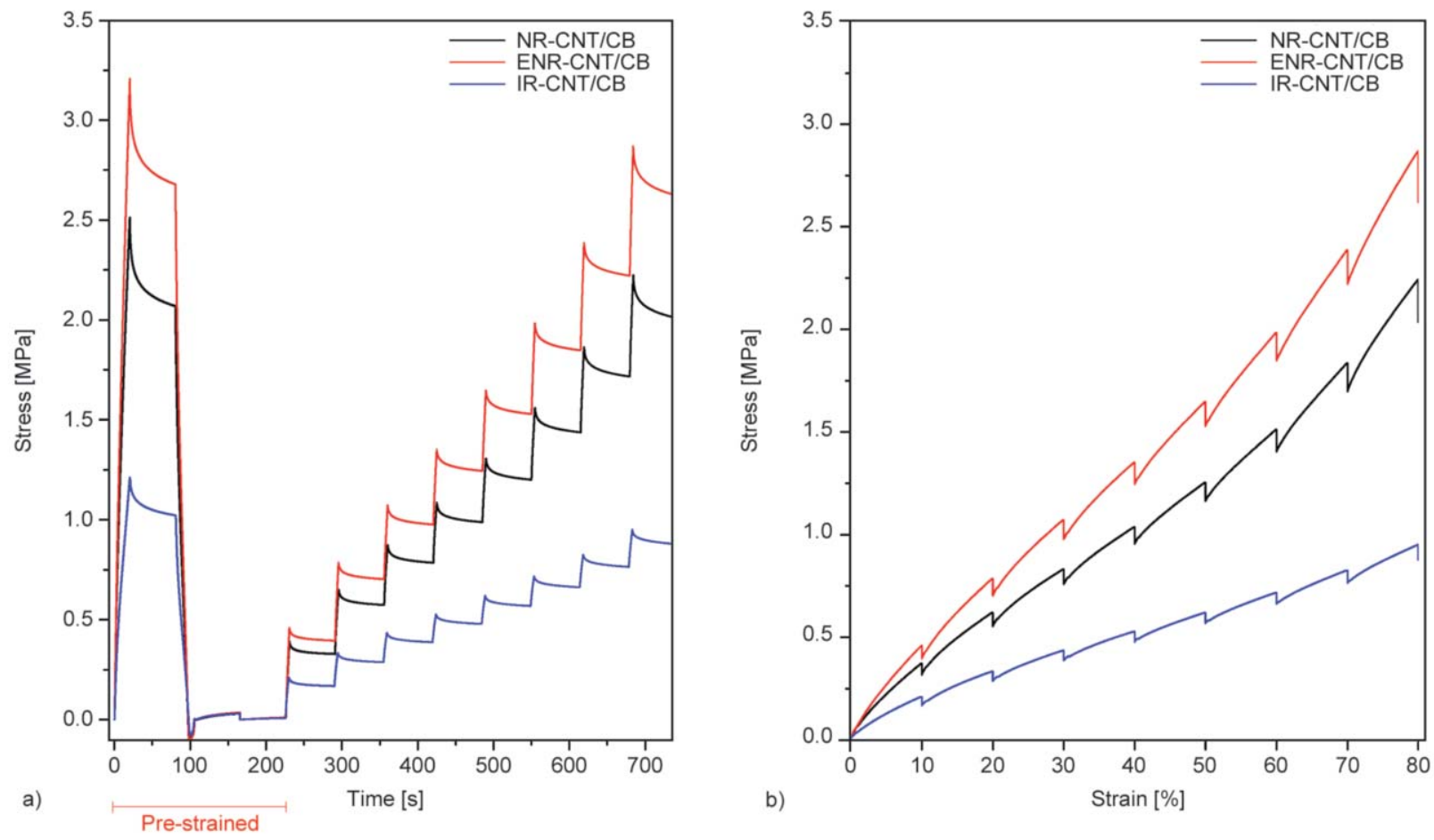

Figure 8. Stress as a function of extension time (a) and of applied strain (b) for the NR, ENR and IR composites with 5 phr of $\mathrm{CNT} / \mathrm{CB}$ hybrid filler. The strain was increased by $10 \%$ stepwise until $80 \%$ maximum before releasing the force to $0 \mathrm{~N}$. 
chemical linkages contributed to the relaxation of the ENR and NR matrices, which had overall better elasticity than the IR matrix.

Relative changes in electrical resistance of the composites are shown in Figure 10, and it different states of resistance are again observed. It is noted that the negative values of relative change are due to the prestraining, which released some rubber filler bonds. This facilitates the rotation of filler particles to form new filler-filler contacts in the rubber matrix [24], and these can decrease the resistance. It is also seen in Figure 10 that the ENR-CNT/CB composites exhibited the most stable resistances, while the NR$\mathrm{CNT} / \mathrm{CB}$ and IR-CNT/CB showed strong increases, particularly past $40 \%$ strain. The results for ENR$\mathrm{CNT} / \mathrm{CB}$ are in a good agreement with the changes shown in Figure 6, indicating filler pathway breakdown at over $100 \%$ strain. This clearly affirms that strong filler-rubber interactions of polar functional groups on ENR and CNT/CB surfaces cause resistance in filler-filler and filler-rubber deformation during extension processes. On the other hand, in the NR-CNT/CB and IR-CNT/CB composites, resistance changes strongly increased at over $40 \%$ strains. Here, the large deformations broke down filler networks during extension, effectively because of the poor filler-rubber interactions and stress history of the sample due to the short relaxation time of $60 \mathrm{~s}$.

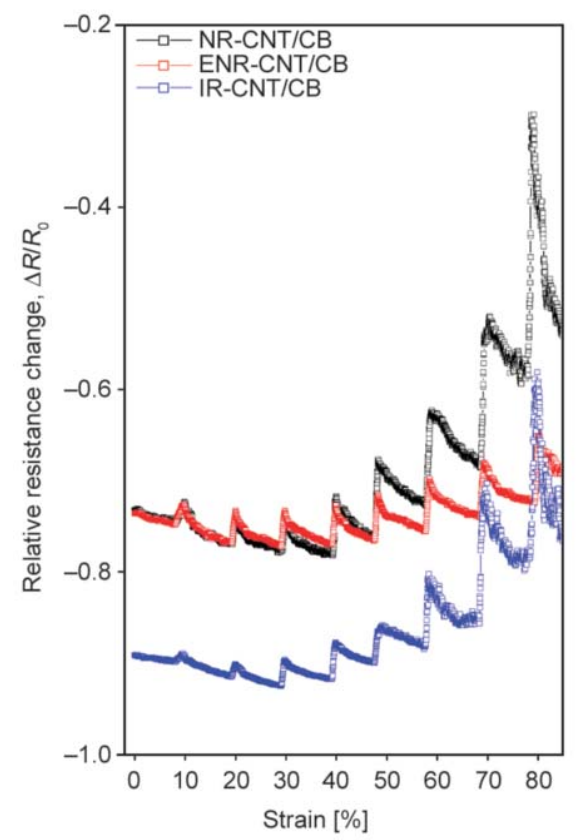

Figure 10. Relative change in electrical resistance as a function applied strain for the NR, ENR and IR composites with $5 \mathrm{phr}$ of CNT/CB hybrid filler.
However, the lesser resistance changes in IR-CNT/ $\mathrm{CB}$ composites might be caused by strong filler agglomeration, which generated fast contacts of filler clusters during extension. Such contacts may have lowered the electrical resistance compared to NRCNT/CB and ENR-CNT/CB composites.

Figure 11 shows the changing of relative resistance changes $\left(\Delta R / R_{0(\max -\min )}\right)$ for the composites during relaxation at each strain level. It is clear that the ENR-CNT/CB composites showed nearly perfect relaxation of resistance during $60 \mathrm{~s}$ of relaxation. This characterizes well the sensor performance of ENR$\mathrm{CNT} / \mathrm{CB}$, which is affected by the chemical linkages that significantly improved elastic relaxation of shape after deformation. As expected, the NR-CNT/ $\mathrm{CB}$ and IR-CNT/CB composites showed strong increases in resistance during relaxation time, particularly at a $40-50 \%$ strain. This means that the sensor function of NR-CNT/CB and IR-CNT/CB composites is strongly perturbed at $50 \%$ strain, and this relates to the poor rubber-filler interactions.

\subsubsection{Dynamic cyclic tensile test}

The dynamic behavior of NR, ENR, and IR composites with CNT/CB hybrid filler were examined under cyclic changes in mechanical stress combined with electrical resistance measurements after some count of cyclic loadings, as shown in Figures 12 and 13,

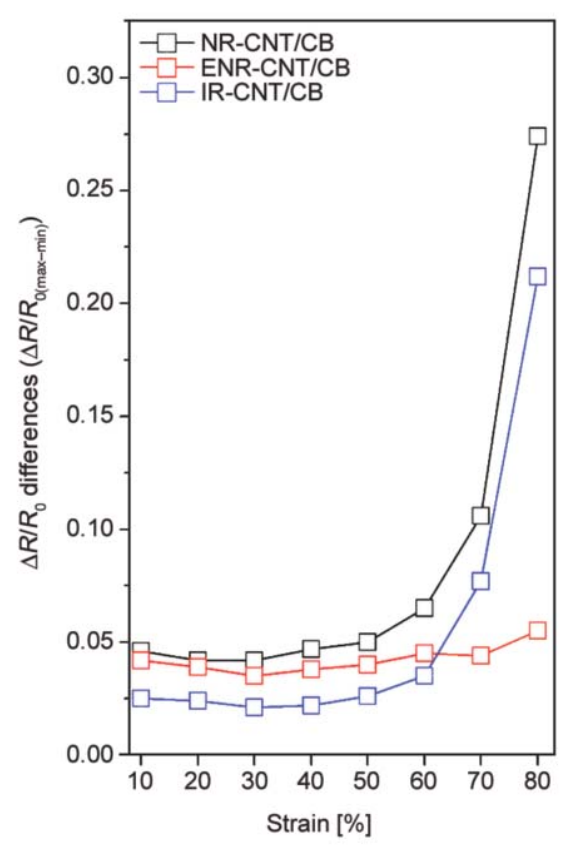

Figure 11. Difference in relative change of resistance at each stress level of the stepwise test for NR, ENR and IR composites with $5 \mathrm{phr}$ of CNT/CB hybrid filler. 

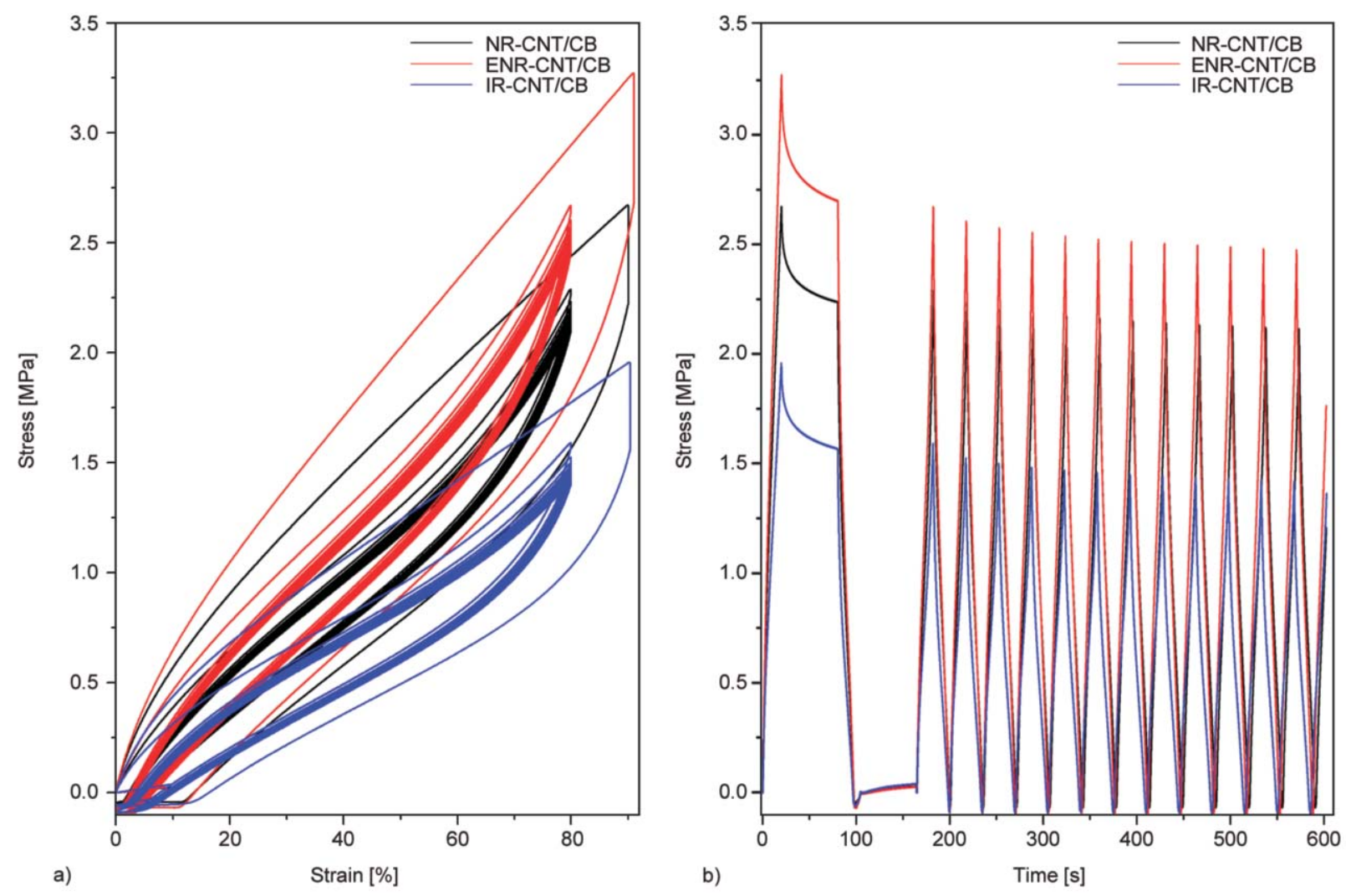

Figure 12. Stress as a function of strain (a) and time (b) for the NR, ENR and IR composites with 5 phr of CNT/CB hybrid filler.

respectively. Here, the samples were cyclically extended for 20 times to $80 \%$ strain during the measuring. Figure 12 shows stress as a function of strain for the composites that had been pre-strained to $90 \%$. It was found that all the composites showed lower stress than in the pre-straining. This is attributed to the detachment of rubber from filler surfaces, which lowers the filler reinforcement efficiency. However, on comparing between the composites, it is clearly seen that the ENR-CNT/CB composites showed the highest stress. This was expected due to the strong filler-rubber interactions from chemical ENR-CNT/ $\mathrm{CB}$ linkages. It is also interesting to consider that the stress at 20 cycles of ENR-CNT/CB and NR-CNT/ $\mathrm{CB}$ still had a higher value than the first cycle of IR$\mathrm{CNT} / \mathrm{CB}$. This means that polarity and non-rubber constituents of ENR and NR strongly affected the mechanical properties of composites, as also observed in Figures 4 and 8.

Figure 13 shows the electrical resistance after cycling the piezoresistive composites for 20 times. It is seen that the resistance changes differed due to polarity and non-rubber constituent effects. In Figure 13, the resistance changes strongly decreased after extending for several times, particularly in NR-CNT/CB and IR-CNT/CB composites. This is due to the detachment of rubber from filler surfaces/sidewalls [26], as seen in the proposed model of Figure 14a. It is seen that the filler-filler clusters in NR and IR matrices were first separated by $80 \%$ strain (confirmed by Figures 6 and 8), and the rubber molecules were then released from filler surfaces in the direction of straining. Thus, filler was free to move without rubber contact and had the opportunity to contact other filler particles, especially during the release of strain. This happened in the IR-CNT/CB composites with strong filler agglomeration and poor filler-rubber interactions. Also, it is seen that both NR-CNT/CB and IR-CNT/CB had a second peak in each strain cycle, whereas this peak was absent for ENR-CNT/CB. This is also due to the poor filler dispersion, which caused fast contact during the release of force and strain, forming new filler contact and showing as the second resistance peak in Figure 13. This confirms that NR-CNT/CB and IR-CNT/CB had poor fillerrubber interactions and strong filler agglomeration, particularly the IR-CNT/CB that had no physical interactions from non-rubber components. On the other hand, ENR-CNT/CB had no second peak (or it was weak). It is noticed in Figure $14 \mathrm{~b}$ that the 

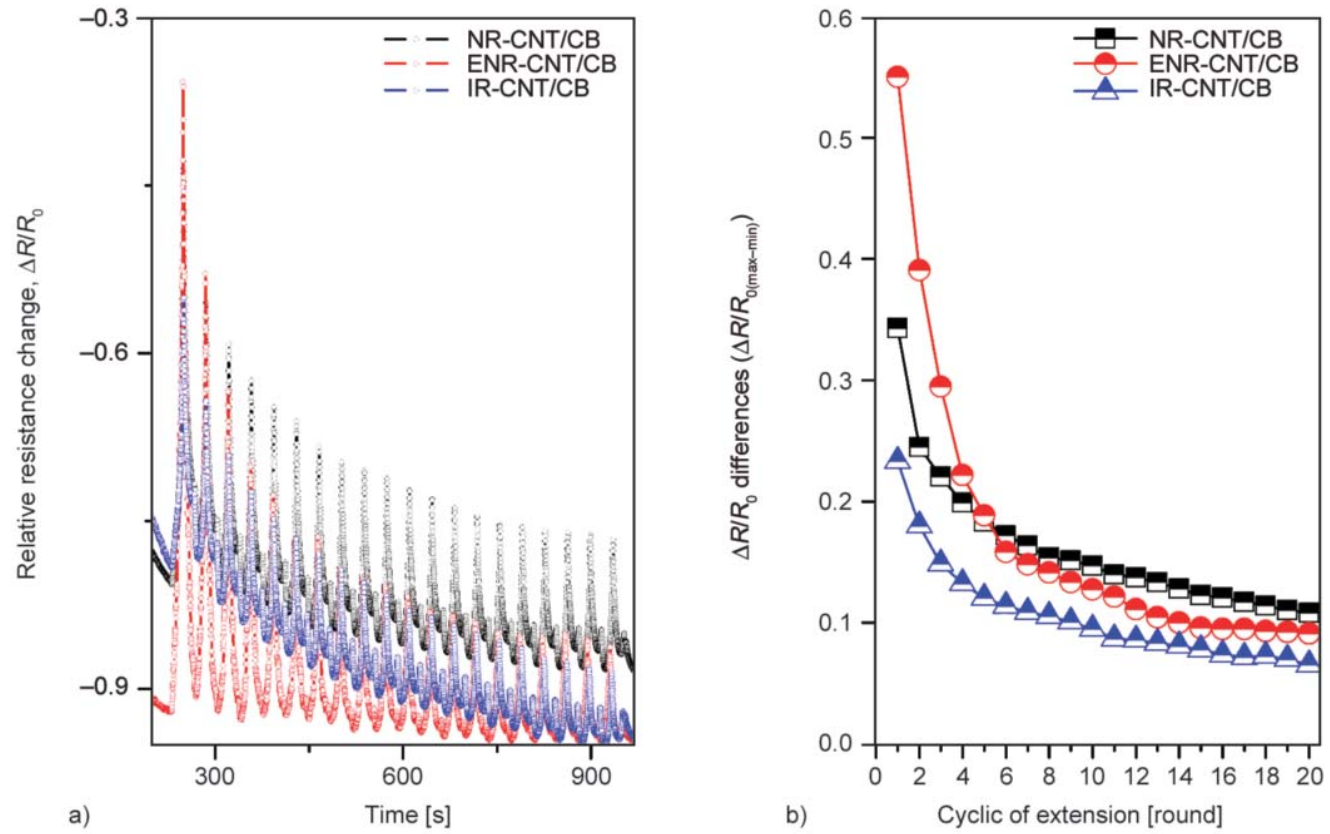

Figure 13. Relative resistance change as a function of time (a), and difference in relative resistance change at each extension cycle (b) for NR, ENR and IR composites with $5 \mathrm{phr}$ of CNT/CB hybrid filler.

ENR-CNT/CB linkages provided composites to the original resistance changes after extension due to high elasticity based on non-detachment of rubber molecules on filler surfaces. Thus, CNT/CB composites based on the ENR matrix could better serve as strain sensors than those with NR and IR matrices. However, physical interactions of non-rubber components in NR might also protect against strong filler agglomeration seen in IR-CNT/CB. Therefore, the strongest resistance changes were in the IR-CNT/CB composites.

Also, the sensor capability of the composites can be examined by considering the difference of maximal and minimal relative changes in electrical resistance $\left(\Delta R / R_{0(\max -\mathrm{min})}\right)$ during each cycle of extension, as exhibited in Figure 13b. It is seen that the ENR-CNT/ $\mathrm{CB}$ showed strong decrease of $\Delta R / R_{0(\max -\min )}$ at $1-6$ rounds of cyclic extension. This might be due to the detachment of NR absorbed on CNT/CCB surfaces, that remained in the composites despite prestraining. This happened less in the NR-CNT/CB and IR-CNT/CB cases. However, it is seen that the $\Delta R / R_{0(\max -\min )}$ of ENR-CNT/CB composites is constant after 12 cycles, whereas $\Delta R / R_{0(\max -\min )}$ of NR-CNT/CB and IR-CNT/CB still significantly decrease. This means that ENR-CNT/CB achieved a stable electrical efficiency after 20 extension cycles to $80 \%$ strain. This is operated by the remaining of attached ENR molecules on CNT/CB surface through ENR-CNT/CB linkages, which resists the deformation of the composites effectively during extending.

However, to assess the effects of longer-term deformations on the composites, dynamic cyclic tensile testing with $50 \%$ strain for 50, 100, 500, 1000, 3000, 5000 , and 10000 cycles was performed, using $200 \mathrm{~mm} / \mathrm{min}$ extension speed. Here, the resistances of composites after each run were measured and converted to electrical conductivity with Equation (2). Figure 15 shows the electrical conductivity as a function of cycle count for NR, ENR, and IR composites with CNT/CB hybrid filler. It is seen that the conductivity decreased with cycle count. Here, the linkages in ENR composites gave the least loss of conductivity. It was found that the conductivity becomes stable after 3000 cycles (from 15.4 to $0.044 \mu \mathrm{S} / \mathrm{cm}$ at 3000 rounds). This is similar to the NR-CNT/CB composites, while fewer cycles were needed for IR$\mathrm{CNT} / \mathrm{CB}$ owing to strong filler agglomeration and poor filler-rubber interactions. In summary, the ENR$\mathrm{CNT} / \mathrm{CB}$ composites are the ones best suited for strain sensor applications and also the flexible electrode and actuator used in the electronic devices, due to high elasticity (Figure 2), electrical conductivity (Figure 3), mechanical properties (Figures 4, 7, 9 and 12), and recovery of electric resistance under static (Figures 10 and 11) and dynamic (Figures 13) tensile loading. This is attributed to the polar chemical interactions between ENR and functional groups on CNT/CB surfaces [35]. Furthermore, the non-rubber 


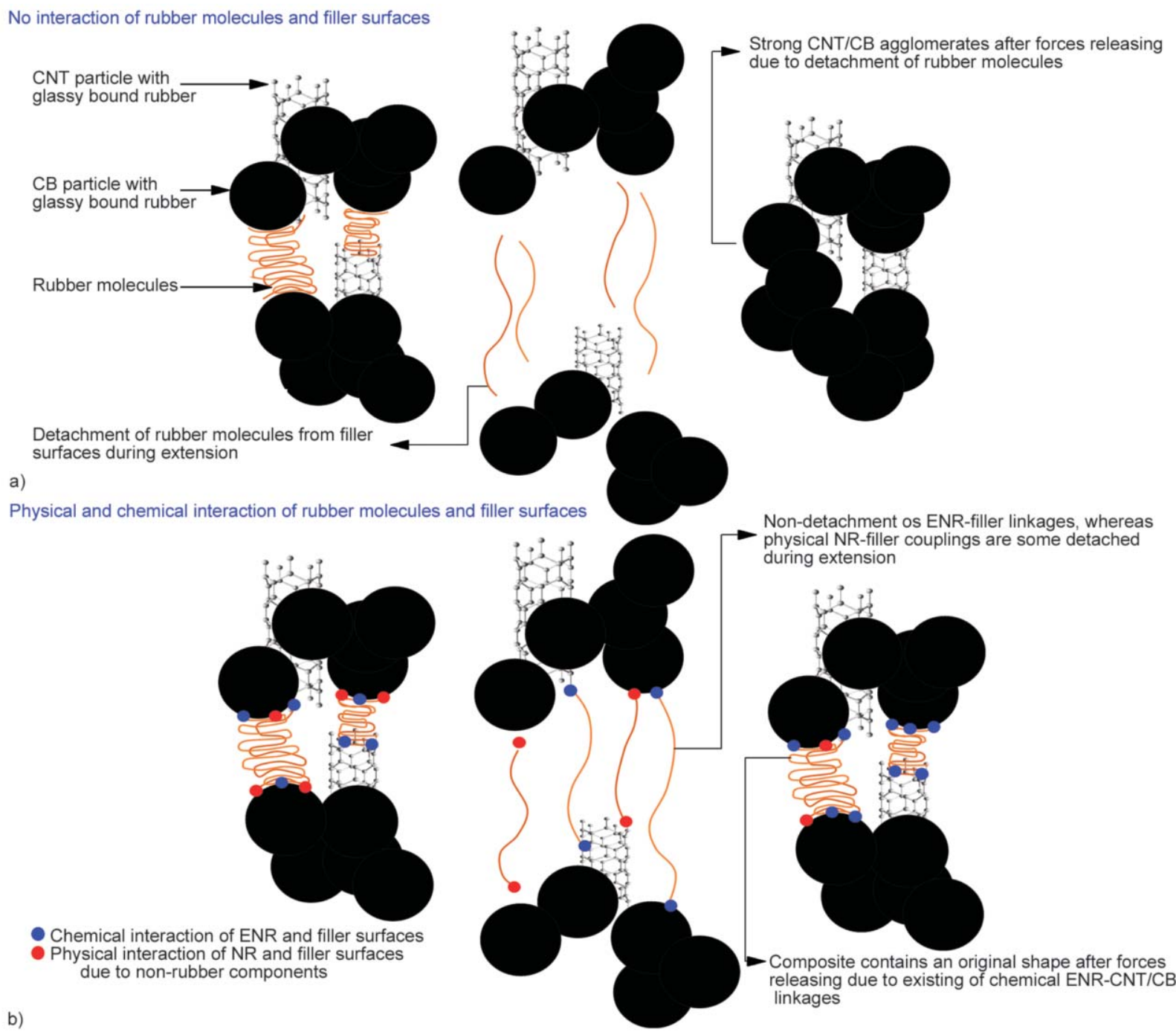

Figure 14. A proposed model of composites at before, during and after extension at $80 \%$ strain for 20 cycles compared between composites (a) with no interaction, and (b) with chemical and physical interactions of rubber molecules and filler surfaces.

components in NR and ENR matrices improved the filler dispersion, as seen in the TEM images of Figure 15. It is clear that the dispersion of CNT/CB particles/clusters was homogeneous in the ENR matrix, whereas poor $\mathrm{CNT} / \mathrm{CB}$ dispersion with strong fillerfiller agglomeration was exhibited in the IR matrix, as expected.

\subsection{Proposed ENR-CNT/CB composites for sensor applications}

Figure 16 shows a proposed model for using ENR$\mathrm{CNT} / \mathrm{CB}$ composites as strain sensors in textiles. Here, an ENR-CNT/CB sheet of size $0.5 \times 3.0 \times$ $0.1 \mathrm{~cm}^{3}$ was fabricated and connected to wire coils at two opposing sides of the sensor, using epoxy glue mixed with silver paint coating. These wires were multi-connected directly to the detector, which will send the data automatically to the main computer via
Bluetooth. For connecting the sensor to the textile surface, highly concentrated NR latex with $60 \%$ dry rubber content (DRC) was sprayed on top of the sensor and the wires. This also protects against moisture. This sensor can serve as a motion sensor in clothes for health monitoring, with high elasticity (Figure 2) and good mechanical properties (Figures 4, 8, 9 and 12) compared to the sensor prepared by using thermoplastic elastomer [27], and high conductivity together with low percolation threshold concentration (Figure 3), as well as suitable recovery from static and dynamic tensile loads (Figures 11, 13 and 15).

\section{Conclusions}

NR, ENR, and IR composites with CNT/CB hybrid filler were prepared using an internal mixer and a two-roll mill. It was found that the polarity of ENR and the non-rubber components (protein 

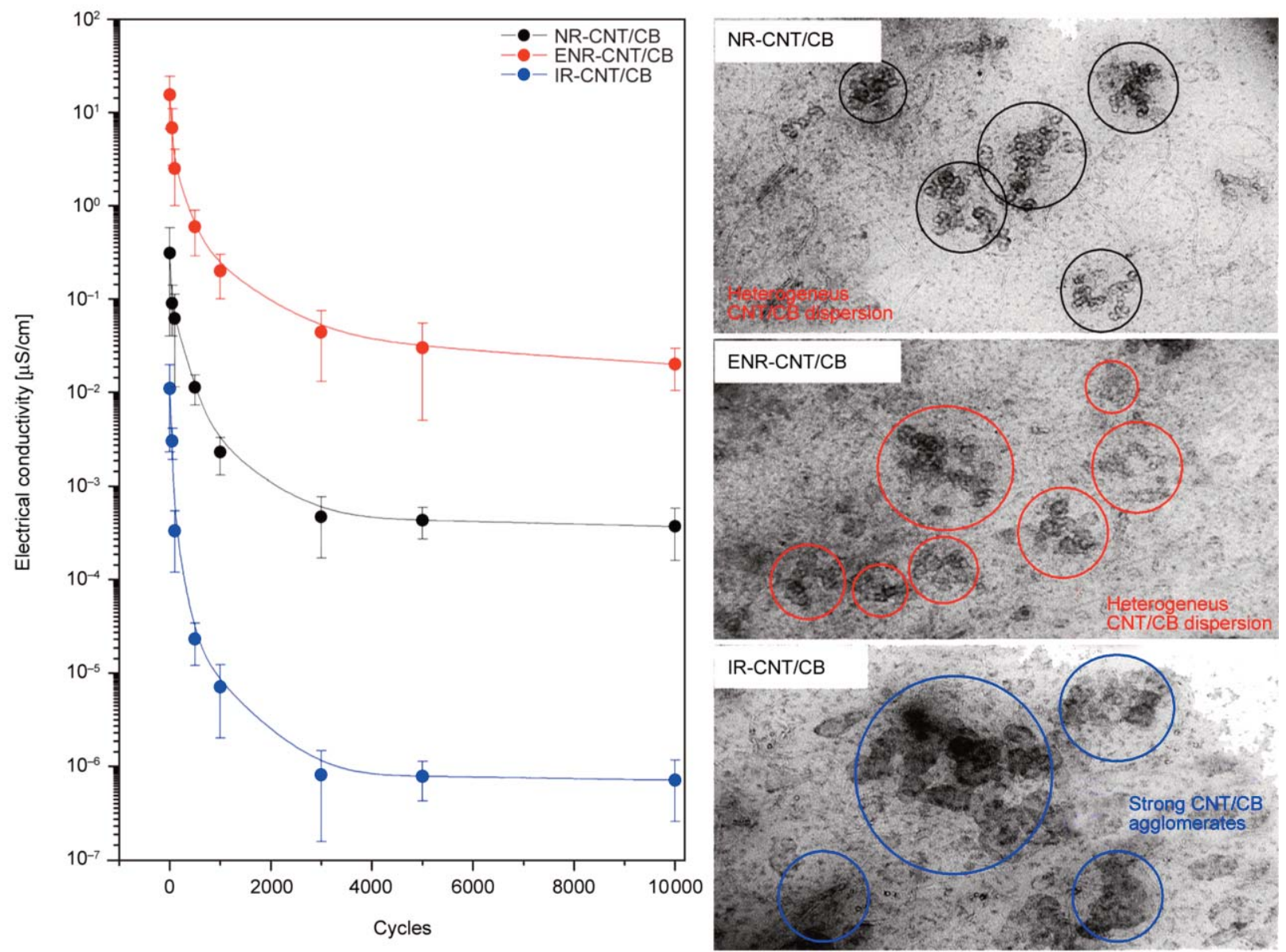

Figure 15. Electrical conductivity of NR, ENR and IR composites with $5 \mathrm{phr}$ of CNT/CB hybrid filler compared after 0,50 , $100,300,500,1000,3000,5000$ and 10000 cycles of extensional strain, together with TEM images at the same magnification of $50000 \times$.

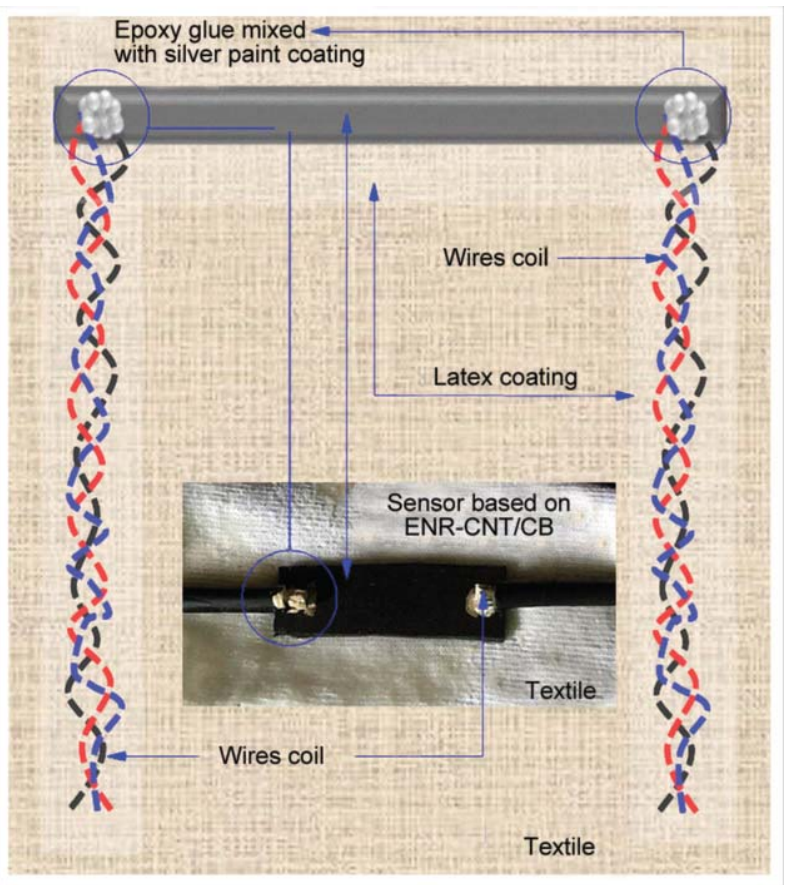

Figure 16. A demonstration of using ENR-CNT/CB composite as a strain sensor fixed on textile. and phospholipids) in NR affected composite properties. It was observed that chemical interactions between the polar functional groups of ENR and the $\mathrm{CNT} / \mathrm{CB}$ surfaces gave higher elasticity and mechanical properties than those of the NR-CNT/CB and IR-CNT/CB composites. In particular, the ENR$\mathrm{CNT} / \mathrm{CB}$ composites recovered nearly the initial electrical resistance after 20 cycles of extension to $80 \%$ strain and had changed after 10000 cycles to $50 \%$ strain before keeping constant of resistivity in the range of semi-conductive material. Therefore, the ENR-CNT/CB composite is proposed as the best choice for strain sensor applications, based on assessed mechanical properties, conductivity, recoverability under static and dynamic tensile loads, together with cost-effectiveness and ease of processing. Also, it was found that the non-rubber constituents (protein and phospholipids) in NR improved filler dispersion and provided better mechanical properties, electrical conductivity, and also recovery than those of the IR-CNT/CB composites. Overall, it can 
be summarized that polarity and non-rubber components in the rubber matrix both influence properties relevant to sensor applications, not only elasticity, mechanical properties, and electrical conductivity, but also static and dynamic recoveries, which are key aspects on producing strain sensors.

\section{Acknowledgements}

The authors gratefully acknowledge financial support in the form of a Royal Golden Jubilee Advanced Programme: No. RAP60K0013 (2.RT.PS/60/1.Ad). Also, the Faculty of Science and Industrial Technology, Prince of Songkla University Surat Thani Campus, Department of Chemistry, King Mongkut's University of Technology Thonburi and EMPA Dübendorf are acknowledged for access to facilities and equipment. Also, we would like to thank Assoc. Prof. Dr. Seppo Karrila for proof-reading and Mr. Tobias Renze for piezoresistivity measurements.

\section{References}

[1] Ma P-C., Siddiqui N. A., Marom G., Kim J-K.: Dispersion and functionalization of carbon nanotubes for polymer-based nanocomposites: A review. Composites Part A: Applied Science and Manufacturing, 41, 1345 1367 (2010).

https://doi.org/10.1016/j.compositesa.2010.07.003

[2] Bokobza L.: Multiwall carbon nanotube elastomeric composites: A review. Polymer, 48, 4907-4920 (2007). https://doi.org/10.1016/j.polymer.2007.06.046

[3] Li C., Thostenson E. T., Chou T-W.: Dominant role of tunneling resistance in the electrical conductivity of carbon nanotube-based composites. Applied Physics Letters, 91, 223114/1-223114/3 (2007).

https://doi.org/10.1063/1.2819690

[4] Yamada T., Hayamizu Y., Yamamoto Y., Yomogida Y., Izadi-Najafabadi A., Futaba D. N., Hata K.: A stretchable carbon nanotube strain sensor for human-motion detection. Nature Nanotechnology, 6, 296-301 (2011). https://doi.org/10.1038/nnano.2011.36

[5] Ma P-C., Liu M-Y., Zhang H., Wang S-Q., Wang R., Wang K., Wong Y-K., Tang B-Z., Hong S-H., Paik K-W., Kim J-K.: Enhanced electrical conductivity of nanocomposites containing hybrid fillers of carbon nanotubes and carbon black. ACS Applied Materials and Interfaces, 1, 1090-1096 (2009).

https://doi.org/10.1021/am9000503

[6] Zhang S. M., Lin L., Deng H., Gao X., Bilotti E., Peijs T., Zhang Q., Fu Q.: Synergistic effect in conductive networks constructed with carbon nanofillers in different dimensions. Express Polymer Letters, 6, 159-168 (2012).

https://doi.org/10.3144/expresspolymlett.2012.17
[7] Kim K-S., Rhee K-Y., Lee K-H., Byun J-H., Park S-J.: Rheological behaviors and mechanical properties of graphite nanoplate/carbon nanotube-filled epoxy nanocomposites. Journal of Industrial and Engineering Chemistry, 16, 572-576 (2010).

https://doi.org/10.1016/j.jiec.2010.03.017

[8] Wang J., Zhang K., Cheng Z., Lavorgna M., Xia H.: Graphene/carbon black/natural rubber composites prepared by a wet compounding and latex mixing process. Plastics, Rubber and Composites, 47, 398-412 (2018). https://doi.org/10.1080/14658011.2018.1516435

[9] Nakaramontri Y., Kummerlöwe C., Nakason C., Vennemann N.: The effect of surface functionalization of carbon nanotubes on properties of natural rubber/carbon nanotube composite. Polymer Composites, 36, 2113-2122 (2015).

https://doi.org/10.1002/pc.23122

[10] Iijima S.: Helical microtubules of graphitic carbon. Nature, 345, 56-58 (1991). https://doi.org/10.1038/354056a0

[11] Nakaramontri Y., Nakason C., Kummerlöwe C., Vennemann N.: Influence of modified natural rubber on properties of natural rubber-carbon nanotube composites. Rubber Chemistry and Technology, 88, 199-218 (2015).

https://doi.org/10.5254/rct.14.85949

[12] Natarajan T. S., Eshwaran S. B., Stöckelhuber K. W., Wießner S., Pötschke P., Heinrich G., Das A.: Strong strain sensing performance of natural rubber nanocomposites. ACS Applied Materials and Interfaces, 95, 4860-4872 (2017). https://doi.org/10.1021/acsami.6b13074

[13] Potts J. R., Dreyer D. R., Bielawski C. W., Ruoff R. S.: Graphene-based polymer nanocomposites. Polymer, 52, 5-25 (2011). https://doi.org/10.1016/j.polymer.2010.11.042

[14] Sau K. P., Chaki T. K., Khastgir D.: Electrical and mechanical properties of conducting carbon black filled composites based on rubber and rubber blends. Journal of Applied Polymer Sciences, 71, 887-895 (1999). https://doi.org/10.1002/(SICI)10974628(19990207)71:6<887::AID-APP4>3.0.CO;2-D

[15] Sumfleth J., Adroher X. C., Schulte K.: Synergistic effects in network formation and electrical properties of hybrid epoxy nanocomposites containing multi-wall carbon nanotubes and carbon black. Journal of Materials Science, 44, 3241-3247 (2009). https://doi.org/10.1007/s10853-009-3434-7

[16] Lee J-H., Kim S. K., Kim N. H.: Effects of the addition of multi-walled carbon nanotubes on the positive temperature coefficient characteristics of carbon-blackfilled high-density polyethylene nanocomposites. Scripta Materialia, 55, 1119-1122 (2006). https://doi.org/10.1016/j.scriptamat.2006.08.051 
[17] Dang Z-M., Shehzad K., Zha J-W., Mujahid A., Hussain T., Nie J., Shi C-Y.: Complementary percolation characteristics of carbon fillers based electrically percolative thermoplastic elastomer composites. Composites Science and Technology, 72, 28-35 (2011). https://doi.org/10.1016/j.compscitech.2011.08.020

[18] Nakaramontri Y., Pichaiyut S., Wisunthorn S., Nakason C.: Hybrid carbon nanotubes and conductive carbon black in natural rubber composites to enhance electrical conductivity by reducing gaps separating carbon nanotube encapsulates. European Polymer Journal, 90, 467 484 (2017).

https://doi.org/10.1016/j.eurpolymj.2017.03.029

[19] Zhang X. W., Pan Y., Zheng Q., Yi X. S.: Piezoresistance of conductor filled insulator composites. Polymer International, 50, 229-236 (2001).

https://doi.org/10.1002/1097-0126(200102)50:2<229::AIDPI612>3.0.CO;2-U

[20] Zhao J. H., Dai K., Liu C., Zheng G., Wang B., Liu C., Chen J., Shen C.: A comparison between strain sensing behaviors of carbon black/polypropylene and carbon nanotubes/polypropylene electrically conductive composites. Composites Part A: Applied Science and Manufacturing, 48, 129-136 (2013).

https://doi.org/10.1016/j.compositesa.2013.01.004

[21] Nakaramontri Y., Nakason C., Kummerlöwe C., Vennemann N.: Effects of in-situ functionalization of carbon nanotubes with bis(triethoxysilylpropyl) tetrasulfide (TESPT) and 3-aminopropyltriethoxysilane (APTES) on properties of epoxidized natural rubbercarbon nanotube composites. Polymer Engineering and Science, 55, 2500-2510 (2016).

https://doi.org/10.1002/pen.24140

[22] Selvan N. T., Eshwaran S. B., Das A., Stöckelhuber K. W., Wießner S., Pötschke P., Nando G. B., Chervanyov A. I., Heinrich G.: Piezoresistive natural rubber-multiwall carbon nanotube nanocomposite for sensor applications. Sensors and Actuators A: Physical, 239, 102113 (2016).

https://doi.org/10.1016/j.sna.2016.01.004

[23] Melnykowycz M., Koll B., Scharf D., Clemens F.: Comparison of piezoresistive monofilament polymer sensors. Sensors, 14, 1278-1294 (2014).

https://doi.org/10.3390/s140101278

[24] Culha U., Nurzaman S. G., Clemens F., Iida F.: SVAS ${ }^{3}$ : Strain vector aided sensorization of soft structures. Sensors, 14, 12748-12770 (2014).

https://doi.org/10.3390/s140712748

[25] Melnykowycz M., Tschudin M., Clemens F.: Piezoresistive soft condensed matter sensor for body-mounted vital function applications. Sensors, 16, 326-335 (2016). https://doi.org/10.3390/s16030326

[26] Subramaniam K., Das A., Stöckelhuber K. W., Heinrich G.: Elastomer composites based on carbon nanotubes and ionic liquid. Composites Science and Technology, 86, 367-400 (2013).

https://doi.org/10.5254/rct.13.86984
[27] Mattmann C., Clemens F., Tröster G.: Sensor for measuring strain in textile. Sensors, 8, 3719-3732 (2008). https://doi.org/10.3390/s8063719

[28] Nakaramontri Y., Kummerlöwe C., Vennemann N., Wisunthorn S., Pichaiyut S., Nakason C.: Electron tunneling in carbon nanotubes and carbon black hybrid filler-filled natural rubber composites: Influence of nonrubber components. Polymer Composites, 39, 12371250 (2018). https://doi.org/10.1002/pc.24821

[29] Stöckelhuber K. W., Das A., Jurk R., Heinrich G.: Contribution of physico-chemical properties of interfaces on dispersibility, adhesion and flocculation of filler particles in rubber. Polymer, 51, 1954-1963 (2010). https://doi.org/10.1016/j.polymer.2010.03.013

[30] Le H. H., Pham T., Henning S., Klehm J., Wießner S., Stöckelhuber K-W., Das A., Hoang X. T., Do Q. K., Wu M., Vennemann N., Heinrich G., Radusch H-J.: Formation and stability of carbon nanotube network in natural rubber: Effect of non-rubber components. Polymer, 73, 111-121 (2015). https://doi.org/10.1016/j.polymer.2015.07.044

[31] Kummerlöwe C., Vennemann N., Pieper S., Siebert A., Nakaramontri Y.: Preparation and properties of carbonnanotube composites with natural rubber and epoxidized natural rubber. Polymer Engineering and Science, 59, 11-12 (2014).

https://doi.org/10.14314/polimery.2014.811

[32] Bautista-Quijano J. R., Pötschke P., Brünig H., Heinrich G.: Strain sensing, electrical and mechanical properties of polycarbonate/multiwall carbon nanotube monofilament fibers fabricated by melt spinning. Polymer, 82, 181-189 (2016).

https://doi.org/10.1016/j.polymer.2015.11.030

[33] Ahirwal D., Palza H., Schlatter G., Wilhelm M.: New way to characterize the percolation threshold of polyethylene and carbon nanotube polymer composites using Fourier transform (FT) rheology. Korea-Australia Rheology Journal, 26, 319-326 (2014). https://doi.org/10.1007/s13367-014-0036-y

[34] Palza H., Zapata P., Sagredo C.: Shape memory composites based on a thermoplastic elastomer polyethylene with carbon nanostructures stimulated by heat and solar radiation having piezoresistive behavior. Polymer International, 67, 1046-1053 (2018).

https://doi.org/10.1002/pi.5610

[35] Nakaramontri Y., Kummerlöwe C., Vennemann N., Wisunthorn S., Pichaiyut S., Nakason C.: Effect of bis(triethoxysilylpropyl) tetrasulfide (TESPT) on properties of carbon nanotubes and conductive carbon black hybrid filler filled natural rubber nanocomposites. Express Polymer Letters, 12, 867-884 (2018). https://doi.org/10.3144/expresspolymlett.2018.75 